\title{
MULTILETRAMENTOS NAS REDES SOCIAIS: O PAPEL DOS EMOTICONS NO PROCESSO DE SIGNIFICAÇÃO
}

Raisa Rodrigues da Fonseca

\section{RESUMO:}

Vivemos uma era em que, à ainda presente cultura do papel, vem sendo adicionada a cultura da tela, ou cibercultura. Assim, com o advento de novas tecnologias digitais, múltiplas práticas e gêneros emergem na sociedade e a comunicação passa a independer cada vez mais da proximidade física, surgindo novas formas de interação, dentre elas as redes sociais de relacionamento. Com isso, muitos recursos não verbais são agregados à comunicação, complementando a codificação da mensagem e a transmissão das emoções dos falantes. Tais recursos contam com ferramentas inovadoras, como, por exemplo, os emoticons, objeto de análise desse trabalho, os quais, para significar, podem ou não se associar a outros recursos de linguagem. A hibridização de diversas modalidades linguísticas permite-nos refletir sobre as tendências multimodais, vez que essas não significam dissociadamente. Diante de tais inovações, faz-se razoável pensar em propiciar aos alunos o acesso às novas ferramentas, recursos tecnológicos e digitais, a fim de conduzi-los a exercitar uma comunicação eficaz que não se limite apenas a textos escritos. Pensando nisso, este trabalho pretende apresentar uma proposta didática sob o prisma dos multiletramentos, considerando como tal perspectiva pode ser trabalhada em sala de aula com as multimodalidades propiciadas pelas ferramentas emoticon inseridas no contexto das redes sociais.

Palavras-chave: multiletramentos, multimodalidades, emoticons.

\section{INTRODUÇÃO}

Novos desafios permeiam o ensino de línguas atualmente. O ritmo frenético das mudanças sociais impulsionou novas formas de conceber o ensino e novas propostas metodológicas. Mesmo que num ritmo bem mais lento, de forma geral, em comparação com as práticas sociais do cotidiano, a escola não deixa de sentir o impacto e os efeitos das relações humanas e capitalistas em constante transformação. Dessa forma, muito se tem refletido sobre a educação.

Com os avanços tecnológicos, novos gêneros, novas linguagens, novos formatos emergem na sociedade, assumem um ritmo crescente e quase incontrolável que permitem aos usuários olhar a si, a sociedade e o mundo de outras formas, delineando novos rumos sociais, culturais e econômicos.

Com efeito, nada tem causado tamanho impacto e tantas mudanças quanto às novas tecnologias. Parte dessas mudanças deve-se às redes sociais, uma vez que há liberdade para interagir, criar e inúmeras possibilidades de usos, tornando a comunicação mais ágil, eficaz e acessível. Essa agilidade, facilidade e interação em tempo real, dá-nos a sensação de mudanças constantes, rápidas, súbitas. Destarte, podemos inferir que já não vivemos mais sem a tecnologia e sem determinadas ferramentas. E se, o docente já depende dessas ferramentas digitais para se comunicar, 


\section{SEMINÁRIO DE PESQUISA EM CIÊNCIAS HUMANAS - SEPECH \\ Humanidades, Estado e desafios didático-científicos \\ Londrina, 27 a 29 de julho de 2016}

interagir, preparar aulas, elaborar provas, entre outras atividades, certamente que seus alunos dependem ainda mais de tais ferramentas, pois em regra, estão bem à frente de seus professores no que se refere às tecnologias. Em consequência disso, o processo de ensino-aprendizagem têm passado por modificações significantes, levando estudiosos da educação a analisarem e investigarem os efeitos dessas novas práticas sociais e o uso crescente dessa linguagem na sociedade.

Diante desse "moderno" e "multi" mundo que vivenciamos, percebendo as influências e necessidades que as redes sociais têm assumido em nosso cotidiano, faz-se necessário o trabalho com as ferramentas existentes nas redes sociais, para então, ser possível propiciar aos alunos um material profícuo, partindo dos conhecimentos e habilidades prévias dos mesmos. Tendo em vista que uma das redes sociais mais utilizadas pelos brasileiros é o Facebook, e com base na observação do uso dessa rede, optamos pela elaboração de uma proposta didática que desperte no aluno um olhar mais atento para o uso dos emoticons nesta rede social, considerando que este recurso é muito utilizado não somente na rede em questão, mas em todas, e que o adolescente/jovem sabe manusear.

Nesse trabalho, buscamos apresentar uma proposta didática, dentro da perspectiva teórica e prática dos multiletramentos, verificar e analisar o uso dos emoticons pelos usuários, os alunos, especificamente na rede social Facebook, atentando-se às simultaneidades de diferentes competências e o contexto em que essa ferramenta está sendo empregada, o que será exposto nos próximos tópicos.

\section{A LEITURA E A ESCRITA NA ERA DIGITAL: O CONCEITO DE MULTILETRAMENTOS}

O ambiente virtual é formado por inúmeras ferramentas e recursos tecnológicos, os quais já há algum tempo fazem parte do nosso cotidiano. Atualmente, já é possível pensar que esse ambiente é quase uma abstração das salas de aula, onde os alunos podem adquirir conhecimentos e habilidades por meio de múltiplas mídias e ferramentas de comunicação. Sendo assim, fica claro que é necessário atentar para a conjuntura de como são utilizadas essas ferramentas tecnológicas e para quais finalidades, com o intuito de que, assim procedendo, seja possível trabalhar com parte das culturas de referência do alunado, com gêneros, mídias e linguagem por ele apreendidos.

É preciso alçar um enfoque pluralista, ético, democrático, crítico, autônomo e, assim, alfabetizar, "letrar" e, mais profundamente, "multiletrar" nossos alunos, uma vez que novos tempos demandam novas práticas, novos letramentos, segundo parecer de Rojo (2009). Aliás, atualmente essas parecem ser, com efeito, as duas principais prioridades às quais a escola, teoricamente, necessita se voltar: alfabetizar e letrar pessoas.

Para dar conta das novas demandas da sociedade contemporânea, um grupo de pesquisadores dos letramentos, em um colóquio do Grupo de Nova Londres (EUA) no ano de 1996, publicaram um manifesto denominado: "Uma pedagogia dos multiletramentos - desenhando futuros sociais" (ROJO, 2012, p. 12) reconhecendo que a escola deveria se responsabilizar em propiciar aos seus alunos os novos letramentos emergentes na sociedade atual e de levar em consideração as variadas culturas presentes 


\section{SEMINÁRIO DE PESQUISA EM CIÊNCIAS HUMANAS - SEPECH \\ Humanidades, Estado e desafios didático-científicos \\ Londrina, 27 a 29 de julho de 2016}

nas salas de aula, bem como os textos digitais, multimodais, multissemióticos. Essas novas configurações motivaram um conceito mais amplo acerca dos letramentos das letras, da imagem e do som - assim surgem os multiletramentos.

As discussões e estudos sobre a pedagogia dos multiletramentos acontecem há duas décadas, porém no Brasil passou-se a analisar mais profundamente o conceito a partir do ano de 2006. A professora Roxane Rojo, pesquisadora influente sobre o tema, defende que nos dias atuais letrar o aluno já não é o bastante. Com as novas tecnologias, mídias e profissões que lidam diretamente com sons, imagens, apps e programas, fez-se necessário renovar, reinventar as práticas pedagógicas. Desse modo, não somente letrar, mas, sobretudo, multiletrar o aluno é trabalhar parte das culturas adquiridas por ele (popular, de massa, local) e considerar seus conhecimentos de gêneros, mídias e linguagens, a fim de buscar um enfoque crítico, ético e autônomo, que envolva discursos e textos aptos a ampliar seu repertório cultural, direcionando-o assim a outros letramentos.

Diante disso, é importante considerar que essas modificações atingiram consideravelmente as práticas de leitura e escrita, pois estas sempre acompanharam as demandas sociais, econômicas, culturais e políticas. Hoje as tecnologias digitais são uma realidade e através delas aparecem novos exercícios de leitura e escrita, desencadeando, por sua vez, novas atitudes sociais e eventos de letramento. Com efeito, o texto já vem perdendo seu caráter único, fechado, nisso a importância de propiciar aos alunos outros letramentos, multiletrando-o.

Com o desenvolvimento das tecnologias, outros gêneros, não presos apenas à escrita, ganham espaço, o que torna o leitor diferente daquele que esteve mais preso à cultura escrita, pois este leitor não conta somente com o texto verbal, mas com outros recursos que complementam a leitura e a interpretação. Esses novos gêneros perdem então sua forma rígida, engessada, pois se permitem serem questionados, dialogados, já que seu caráter não é mais "multi, mas hiper: hipertextos, hipermídias" (ROJO, 2012, p. 21, grifo do autor) e afins. Ou seja, o leitor tem liberdade para interagir com outros textos, imagens e sons, a fim de obter uma interpretação e sentido mais completo, pois a linguagem verbal escrita não é o único foco. Nas palavras da autora,

as imagens e o arranjo de diagramação impregnam e fazem significar os textos contemporâneos (...) é o que tem sido chamado de multimodalidade ou multissemiose dos textos contemporâneos, que exigem multiletramentos. Ou seja, textos compostos de muitas linguagens (ou modos, ou semioses) e que exigem capacidades e práticas de compreensão e produção de cada uma delas (multiletramentos) para fazer significar. (ROJO, 2012, p.19).

Evidentemente, a estrutura em rede $\mathrm{e}$ os formatos hipertextuais $\mathrm{e}$ hipermidiáticos facilitam as apropriações, intensificando as hibridizações, permitindo as colaborações, pois nada é de ninguém, tudo é de todos. Precisamos pensar como as novas tecnologias podem transformar e colaborar no processo de ensino-aprendizagem. O desafio é como a escola, que, tradicionalmente, supervaloriza as coleções clássicas e repertórios desatualizados, faz para se aproximar dos vídeos, áudios, celulares, tablets, em sala de aula. Isso está fora do contexto escolar, não faz parte de seu currículo mas essas ferramentas, podem entrar em diálogo para ensinar os alunos a utilizá-los para 


\section{SEMINÁRIO DE PESQUISA EM CIÊNCIAS HUMANAS - SEPECH \\ Humanidades, Estado e desafios didático-científicos \\ Londrina, 27 a 29 de julho de 2016}

comunicação, navegação, pesquisa, fotografia, enfim, aproveitar os recursos e ferramentas que esses aparelhos proporcionam, e assim, tornar o ensino de Língua Portuguesa mais profícuo e eficaz.

Passaremos agora à proposta de nosso trabalho, qual seja, apresentar um protótipo didático que, partindo de uma ferramenta multimodal, os emoticons, visa trabalhar com os campos dos multiletramentos, atentando ao processo de significação, servindo como instrumento para, possivelmente, suprir as necessidades já aludidas.

\section{OS MULTILETRAMENTOS NA SALA DE AULA: O PROTÓTIPO DIDÁTICO}

Com o advento das tecnologias, surgem novas necessidades: as de apropriar-se das práticas de leitura e escrita, manejá-las com precisão e responder adequadamente às demandas sociais de sua utilização. É nesse ponto que trazemos à tona as discussões sobre os Multiletramentos, pois estas ajudam a tornar as aulas de língua portuguesa mais significativas para o aluno, aproxima a escola à vida, à realidade que cerca o educando e aproxima a língua às práticas sociais.

Considerando o professor o sujeito que precisa refletir sua prática e adequá-la da melhor forma possível à realidade de seus alunos, a educação do século XXI, de forma geral, deve acompanhar o processo de mudança que a sociedade exige como contribuição para a formação e transformação de um novo sujeito, de um sujeito que entenda o mundo que o cerca e que faça uso das várias linguagens de forma útil em seu cotidiano. O conhecimento se dá através do diálogo, na liberdade da troca de informações, na medida em que se tem consciência de uma leitura crítica da realidade que nos cerca, onde a reflexão deve ser um constante devir.

O professor é fundamental em um ensino que pretende formar alunos críticos, emancipadores, conscientes, que vejam e entendam com clareza a importância de saber e dominar sua língua materna, e tornar-se um cidadão apto, ativo em sua comunidade. Para tanto, na era tecnológica que vivemos faz-se necessário uma prática pedagógica mais colaborativa, interativa que apresente uma heterogeneidade da linguagem e da cultura, e que o professor esteja preparado para atuar proficuamente diante destes desafios.

Com base em nossos pressupostos teóricos, os multiletramentos, e por entendermos que esse conceito pode ser eficaz no processo de ensino-aprendizagem, pois aproxima o aluno à realidade que o cerca, optamos por elaborar um protótipo didático usando a ferramenta emoticon, que deriva da junção em inglês das palavras emoticon ${ }^{1}$ (emoção) e icon (ícone). Trata-se de uma sequência de caracteres icônicos, tipográficos, que visam expressar e transmitir um estado mental, emotivo de quem os emprega. Tendo observado os usos dessas ferramentas nas redes sociais, principalmente no Facebook, uma das redes mais acessadas e com maior número de usuários do mundo, inferimos que essa rede apresenta uma infinidade de recursos multimodais, tais como imagens, sons, vídeos, vários aplicativos, entre outros dispositivos que em alguns

\footnotetext{
${ }^{1}$ Informações retiradas do site: < https://www.significadosbr.com.br/o-o >.
} 


\section{SEMINÁRIO DE PESQUISA EM CIÊNCIAS HUMANAS - SEPECH \\ Humanidades, Estado e desafios didático-científicos \\ Londrina, 27 a 29 de julho de 2016}

casos, juntos, são responsáveis por efeitos de sentidos únicos, o que dissociados não teriam o mesmo sentido.

Pensando nos aspectos e definições até então apresentados, buscamos verificar e analisar, de uma forma geral, como os emoticons estão presentes nas redes sociais e como auxiliam no processo de significação, e assim, como esse recurso pode ser trabalhado em sala de aula, uma vez que os emoticons consistem na combinação de caracteres alfanuméricos e imagens que empregados em textos, o torna uma ferramenta semiótica visual, logo, multimodal. Essa junção culmina na representação de gestos faciais reais que contém significados múltiplos, que sensíveis ao contexto e às interpretações, resultam num sentido amplo, completo. A proposta será apresentada no próximo tópico.

\section{O PROTÓTIPO DIDÁTICO: OS EMOTICONS}

Apresentados todos os conceitos base, dos quais partimos para elaboração da proposta em questão, tivemos a preocupação de propor um protótipo didático com o objetivo principal de mostrar aos alunos como estão permeados por multimodalidades e como estas juntas - sons, imagens, letras - constroem e consolidam novos significados, significados estes que sozinhos, isolados não têm o mesmo efeito.

A proposta que delineamos a seguir destina-se a alunos do $6^{\circ}$ ano e até mesmo $7^{\circ}$ ano, do Ensino Fundamental I, uma vez que partimos do pressuposto de que os alunos dessa faixa etária já têm noções de como usar o recurso em análise, os emoticons, atendo-se a multimodalidade que o recurso apresenta, ou seja, hibridização de imagens e signos;

Para melhores resultados na aplicação da proposta, é necessário que os alunos tenham acesso à sala de informática do colégio e que possuam conta rede social Facebook. Como a rede está muito presente no cotidiano do aluno, é interessante que o próprio professor explore se seus alunos utilizam os emoticons em suas páginas e analisar com eles como eles empregam esse recurso. Caso o professor não tenha acesso a sala de informática, é possível seguir com a proposta usando o celular, ou até mesmo tablet, com a devida autorização da coordenação pedagógica do colégio. Muitos alunos já dispõem desses instrumentos, e do aplicativo da rede social nos aparelhos.

\subsection{Justificativa da Proposta}

O interesse em pensar tal proposta consiste em conduzir o aluno a analisar, refletir que está permeado pelas práticas multiletradas e às tendências multimodais que competem os emoticons. Como já elucidado em tópicos anteriores, os emoticons são utilizados para representar, graficamente, algum sentimento que não é possível alçar na completude apenas no texto verbal. Logo, tem-se nesse recurso, um aporte no processo de significação desse texto, o que o torna ferramenta propícia para analisar em sala de aula com os alunos, pois eles têm contato com essa realidade, porém não fazem um uso reflexivo desse recurso, nem analisam a utilidade dessa ferramenta em determinados contextos e como este ajuda na construção de sentidos.

Assim, temos como objetivo geral apresentar uma proposta em que tanto os alunos como os professores, atentem-se para as multimodalidades que nos cercam e 


\section{SEMINÁRIO DE PESQUISA EM CIÊNCIAS HUMANAS - SEPECH \\ Humanidades, Estado e desafios didático-científicos \\ Londrina, 27 a 29 de julho de 2016}

como podemos utilizar ferramentas como os emoticons para complementar e completar os sentimentos que se deseja expressar. Conscientizar os alunos das hibridizações que o permeia é importante, visto que, dado seu contato natural com essas modalidades multimodais, ele já não se atém a essas hibridizações, assim, inferimos que o aluno ainda não tem a sensibilidade para perceber que ao produzir um emoticon, ele (provavelmente) combinou alguns caracteres para assim, gera-lo, resultando num significado que, em determinados contextos, produzem sentidos nem sempre explícitos. Pensamos também em levá-lo a refletir sobre a relação entre palavra, imagem, e outros modos semióticos essenciais para a construção de sentidos, reconhecendo as potencialidades de tais modalidades, conduzindo-os assim a voltarem-se às suas próprias contas do Facebook e refletir os usos desses recursos multimodais e se são cabíveis aos contextos que utilizam.

Tendo como tema de nossa proposta: "Os emoticons no processo de significação", para melhor visibilidade e entendimento, elaboramos a seguir, três etapas para a aplicação da proposta:

\section{ETAPA I: CONTEXTUALIZAÇÃO}

O professor deverá conduzir os alunos à sala de informática, ou utilizar os celulares, como proposto, e iniciar a aula, como motivação, escrevendo na lousa, ou levando impresso, somente os caracteres, atalhos, correspondentes aos emoticons, perguntando a eles se conhecem as imagens correspondentes aos caracteres. Por exemplo:

\begin{tabular}{c|c|}
\hline Nome & Atalho \\
\hline Smile & $:)$ \\
\hline Smile Grande & $: D$ \\
\hline Piscada & $;)$ \\
\hline Olhos alegres & ${ }^{\wedge}$ \\
\hline Rindo & $>: 0$ \\
\hline Riso estranho & $: 3$ \\
\hline Mal-humorado & $>:-($ \\
\hline Triste & $:($ \\
\hline Chorando & $:(1$ \\
\hline Chocado & $: 0$ \\
\hline Cool & $8-I$ \\
\hline Mostrando a língua & $: P$
\end{tabular}

Quadro I - Atalhos para emoticons

Fonte: < http://images.br.sftcdn.net/blog/br/2011/09/Emoticons-Facebook1.png>

Após essa motivação e interação com os alunos, visto que a essa altura, muitos irão se manifestar com as respostas dos caracteres correspondentes, o professor irá percebendo o nível de conhecimento do aluno em relação aos símbolos, atentando-os a como os símbolos alfanuméricos são dispostos para representar uma imagem que, por sua vez, representam um sentimento. Em seguida, o professor poderá trabalhar o 


\section{SEMINÁRIO DE PESQUISA EM CIÊNCIAS HUMANAS - SEPECH \\ Humanidades, Estado e desafios didático-científicos \\ Londrina, 27 a 29 de julho de 2016}

contexto histórico, o que são, como surgiram os emoticons, como eles mudaram e evoluíram com o decorrer do tempo e como hoje não é necessário utilizar os atalhos pois nas redes sociais já tem o recurso pronto, porém ainda é possível utilizá-los; o docente poderá levantar algumas perguntas que conduzirão os alunos a uma reflexão: "Como surgiram essas ferramentas? Na época de seus pais, existiam os emoticons? Como eles expressavam seus sentimentos ao escrever?". Para que o aluno chegue à essas respostas, o professor poderá nesse momento motivar uma pesquisa na internet com os alunos, levantando dados sobre o recurso e analisando se as fontes que colheram informações são confiáveis. O objetivo nessa etapa é que o aluno busque informações sobre os emoticons selecionando informações de fontes confiáveis e dialogue com os colegas e o professor sobre dados dos emoticons como por exemplo, pensando no surgimento deles. Assim, o aluno poderá pensar com o professor e os colegas a função dessa ferramenta, há quanto tempo existe, como era usada inicialmente, como é usada nos dias atuais, enfim, esperasse que ele participe, interaja com o professor e a classe.

\section{ETAPA II: OS USOS DO RECURSO MULTIMODAL}

Nessa etapa, os alunos já têm uma noção sobre a ferramenta em análise, já conhecem sua origem e evolução, assim o professor deverá começar um trabalho de conscientização quanto a tendência multimodal que esse recurso comporta. Explicar ao aluno que ao utilizar esse recurso isoladamente, o efeito não é o mesmo, isto é, para que o emoticon esteja em sua forma concreta, icônica e completa, ele deve estar acompanhado de palavras, de uma frase, um texto.

Tem-se então, a ideia de que esse recurso não significa, completamente, sozinho, a imagem depende do texto, e até mesmo do som algumas vezes, para se consolidar, e assim, ser efetivo na construção de sentido de um texto. Nesse momento, o ideal é que o professor atenha-se à perspectiva base desse trabalho: a dos multiletramentos. Na presente etapa o professor tem o objetivo de mostrar ao aluno que ele está lidando com um recurso que ele tem domínio, porém, é importante considerar que não se trata de um recurso que significa, completamente, isoladamente; trata-se de uma ferramenta que, atrelada ao texto, expande e completa o significado desse. É o que Rojo denomina de multimodalidade, ou seja, o texto atrelado à imagem (emoticon) que resulta num sentido completo do texto. O docente está apresentando ao aluno uma diversidade de modalidades (texto e imagem) que juntas, significam e que são perpassadas por práticas de letramento.

O ideal é apresentar algo mais concreto para o aluno. Como se trata de uma ferramenta que se associa à outras modalidades (escrita, imagem) para significar, é possível que o professor leve alguns recortes de usos destes recursos de um status do Facebook, ou levar uma propaganda, vídeo que ajude a exemplificar esse contexto.

$\mathrm{O}$ aluno está se deparando com uma multimodalidade sem perceber, pois para ele já é normal deparar-se com estes tipos de textos, porém, levá-los a pensar que a imagem e as palavras concretizam o recurso com o intuito de expressar um sentimento, complementando o sentido do texto escrito, exigem capacidades e compreensões que o aluno deve apreender para que possa alçar os sentidos dos textos. Nisso retomamos a importância de não somente letrar o aluno, mas multiletrá-lo como afirma Rojo. 


\section{SEMINÁRIO DE PESQUISA EM CIÊNCIAS HUMANAS - SEPECH \\ Humanidades, Estado e desafios didático-científicos \\ Londrina, 27 a 29 de julho de 2016}

\section{ETAPA III: CONTEXTO}

Por fim, o professor deverá trabalhar com os alunos, os usos dessa ferramenta atentando-os ao contexto. O aluno deverá voltar a sala de informática e acessar sua conta no Facebook, e procurar nas postagens dos alunos, nas mensagens inbox, e em comentários compartilhados, os emoticons e se estes estão sendo utilizados de forma eficiente.

O professor deverá analisar com os alunos como eles mesmos usam os emoticons, e se, em determinadas conversas, o emoticon apresenta o sentido original. Por exemplo, verifique com o aluno se em determinadas frases, o emoticon utilizado reforça a ideia de que o emissor está feliz, ou está sendo irônico; se está enojado ou doente; se está usando o emoticon demonstrando que está rezando ou está usando como um "high five". O professor poderá até mesmo colocar frases que os alunos escreveram no quadro, ou exibir no datashow e analisarem juntos se o contexto comporta o recurso utilizado. O objetivo dessa fase é propiciar ao aluno um espaço para refletir como ele mesmo usa no seu cotidiano a ferramenta emoticon, como o contexto e a interpretação são relevantes na construção de sentidos, e como esse recurso pode ser usado a partir dessas análises.

\section{CONCLUSÃO}

A língua é constitutiva do mundo, logo, ensinar Língua Portuguesa é despertar os usuários para a linguagem como interação, como o lugar de constituição de relações humanas, em que os falantes se tornam cidadãos.

Mediante o que já foi exposto, entendemos que o protótipo didático poderá ajudar o aluno a:

a) Refletir, pensar, analisar sobre os usos multimodais na comunicação, não só com os emoticons mas com as outras modalidades (imagem, sons e letras);

b) Interagir, "traduzindo" e analisando os usos adequados ou não dos emoticons a fim de compreender com precisão as mensagens que circulam as redes sociais;

c) Como as várias modalidades presentes nas postagens dos alunos em suas pages combinam para construir significados, analisando o papel e os usos dos emoticons;

Dadas as atuais demandas, frisamos aqui a ideia de Rojo: faz-se necessário "letrar" e, sobretudo "multiletrar" nossos alunos. Destarte, é lamentável nos depararmos ainda com um ensino de Língua Portuguesa que atua num modelo apenas tradicional, e que, infelizmente, muitos professores ainda não conseguem fugir desta realidade. Pensar, estudar, analisar a prática docente deve ser um trabalho contínuo de adaptação, exploração das necessidades dos alunos, e de posicionar-se como professor mediador, entre o conhecimento e o aluno, a todo instante. Deste modo, pensar em uma prática que vá de encontro à realidade do aluno, levá-los à reflexão e envolvê-los no processo de ensino-aprendizagem, é um desafio constante.

Respondendo aos objetivos desse trabalho, pretendemos desenvolver uma proposta didática que aproximasse o aluno da realidade que ele vive, não usando a tecnologia, as redes sociais e suas ferramentas como mero pretexto, ou para apenas 


\section{SEMINÁRIO DE PESQUISA EM CIÊNCIAS HUMANAS - SEPECH \\ Humanidades, Estado e desafios didático-científicos \\ Londrina, 27 a 29 de julho de 2016}

apresentar uma proposta com um conceito atual que é o multiletramento. A intenção é propor uma didática que envolva o aluno no processo de ensino-aprendizagem de forma natural, partindo de um conhecimento superficial que ele tem das ferramentas que ele usa, mas que não tem ciência de como esse recurso como um todo (unido por imagem, escrita, sons), chega à um significado completo.

À luz desses objetivos, acreditamos que houve aproximação à perspectiva do multiletramento vez que, é possível identificar na proposta, a intenção de conscientizar o aluno sobre os usos das modalidades, quais sejam, palavras e imagens que, juntas, intrínsecas, produzem um sentido a ser transmitido, isto é, temos modalidades híbridas que se separadas, não têm o mesmo sentido e utilidade que juntas culminam. Consideramos também que por se tratar de um recurso mundializado, universal, podemos inferir que os emoticons, enquanto imagens, tornam os discursos mais atrativos por se tratar de uma linguagem divertida, afetiva, emocional, atrativo pros alunos.

Devido a estas novas exigências de nossa sociedade, no que se referem às utilizações práticas dos conhecimentos de leitura e escrita, entendemos que contemplam melhor e mais adequadamente toda essa diversidade, pois são exigidos dos indivíduos os mais diversos conhecimentos quanto ao uso real das modalidades de leitura e escrita, cabendo à escola, como um todo, preparar os alunos para lidar com essas diversidades, com os multiletramentos, ou seja, o contato com as diferentes linguagens presentes nos textos (orais e escritos) atuais.

\section{REFERÊNCIAS:}

GATTI, Bernardete Angelina. Formação de professores no Brasil. Características e problemas. Educação \& Sociedade. Campinas, v. 31, no 113, p. 1355-1379, out-dez. 2010. Disponível em: $<$ http://www.cedes.unicamp.br>. Acesso em: 05. maio. 2015.

LEMKE, Jay. Letramento metamidiático: transformando significados e mídias. Trad. de Clara Dornelles. Trabalhos em Linguistica Aplicada, vol. 49, $\mathrm{n}^{\mathrm{o}}$ 2, p. 455-479, jul/dez, 2010, <http://dx.doi.org/10.1590/S0103-18132010000200009>. Acesso em: 03.mar. 2014.

ROJO, Roxane, \& JURADO, Shirley. A leitura no ensino médio. In: MENDONÇA, Márcia, e BUNZEN, Clécio (orgs.). Português no ensino médio e formação do professor. São Paulo: Parábola Editorial, 2006.

ROJO, Roxane. Letramentos múltiplos, escola e inclusão social, São Paulo: parábola editorial,

2009.

ROJO, Roxane, e MOURA, Eduardo (orgs.). Multiletramentos na escola. São Paulo: Parábola Editorial, 2012. 